\title{
FOREWORD
}

\section{Special Issue on Economics of Water Quality: Challenges, Policies, and Behavioral Mechanisms}

\section{Todd Guilfoos and Emi Uchida}

Few issues are as fundamental to human security and survival as access to a supply of clean, safe drinking water. Yet, more than 650 million people worldwide still used unimproved sources of drinking water in 2015-a significant portion of the population of sub-Saharan Africa and Oceania relied on rivers, lakes, ponds, and irrigation canals (UNICEF, World Health Organization 2015), leading to waterborne diseases such as diarrhea and a high rate of mortality among children. Developed countries also grapple with providing safe water supplies due to aging infrastructure, as illustrated by lead contamination of drinking water in Flint, Michigan. In addition to drinking water, water resources provide ecosystem services such as recreation and wildlife habitat that can be severely affected by contamination. In an assessment of 32 percent of the rivers and streams in the United States, the U.S. Environmental Protection Agency (EPA) (2015) found that the quality of the water supplied by 56 percent of those waterways was inadequate to fully support recreation, habitat, and other designated uses. Degraded water quality worldwide is driven by population growth, expanding industrial and agricultural activities, urbanization, decaying infrastructures, and more-frequent extreme weather events associated with climate change.

\footnotetext{
Todd Guilfoos is an assistant professor and Emi Uchida is an associate professor in the Department of Environmental and Natural Resource Economics at University of Rhode Island. Correspondence: Todd Guilfoos - Department of Environmental and Natural Resource Economics = Kingston Coastal Institute " 1 Greenhouse Road " University of Rhode Island " Kingston, RI 02881 " Phone 1.401.874.2471-Email guilfoos@uri.edu.

We thank the National Institute of Food and Agriculture and the U.S. Department of Agriculture's Agriculture and Food Research Initiative Grant 2014-10057 for financial support of this issue of Agricultural and Resource Economics Review. We also thank the Northeastern Agricultural and Resource Economics Association (NAREA), University of Rhode Island's Kingston Coastal Institute, and the Center for Behavioral and Experimental Agri-Environmental Research for financial support for the NAREA workshop and the NAREA board for their support. Uchida acknowledges support from the National Science Foundation EPSCoR Track-2 Cooperative Agreement IIA-1330406, Collaborative Research: North East Water Resources Network. Additionally, we thank James Opaluch for valuable comments on this foreword.
}

Agricultural and Resource Economics Review 45/2 (August 2016) 209-216

(C) The Author(s) 2016. This is an Open Access article, distributed under the terms of the Creative

Commons Attribution licence (http://creativecommons.org/licenses/by/4.0/), which permits unrestricted re-use, distribution, and reproduction in any medium, provided the original work is 
Increasingly complex water quality problems call for more effective and rational approaches to water quality management. This issue of Agricultural and Resource Economics Review focuses on the economics of water quality, advancing our understanding of policies, valuation, and behavioral economics, which play critical roles in debates about how to assess and address water quality challenges. The studies span from individual decision-making and valuation of water quality to assessing the efficiency of institutions that address nonpoint-source pollution. Advancing nonmarket valuation can not only improve our understanding of nonmarket values but also contribute to improving the performance of institutions.

\section{Managing Nonpoint-source Pollution}

In both developed and developing countries, the most prevalent problem associated with water quality is eutrophication-contamination by nutrients from run-off that choke waterbodies with excessive plant growth (including toxic algal blooms), deprive fish and other species of dissolved oxygen, and sometimes produce toxins. In the United States, eutrophication is caused primarily by nonpoint sources of pollution such as agricultural run-off. Nonpoint-source (NPS) pollution is poorly regulated, and the contamination caused by it remains mostly unmitigated, unlike contamination from point sources, which came under the purview of the Clean Water Act in the 1970s. Given the environmental damage caused by NPS pollution and the high cost associated with remediation and abatement, better ways of managing water quality resources are urgently needed.

Developing safe healthy water supplies and mitigating the effects of existing pollution require vast investments of capital, and the economic tradeoffs can be daunting. In 2009, for example, U.S. agricultural producers supplied crops and livestock worth $\$ 331$ billion to global markets and, concurrently, released a significant amount of NPS pollutants into U.S. rivers and other waterways from their activities (EPA 2009). Consequently, negotiating tradeoffs between the benefits of high-quality water supplies that produce key economic goods and services and the costs of developing, restoring, and maintaining those supplies is a critically important area of economic research.

Economists have identified NPS pollution as the major threat to water systems in the developed world (Olmstead 2010). NPS pollution comes from a variety of sources, including run-off of storm water, fertilizers, and animal waste and old or poorly managed wastewater treatment systems, leading to excess nutrients (e.g., nitrogen and phosphorus) and hypoxia. As shown in Figure 1, more than 400 areas around the world suffered from hypoxic zones in 2008 (Diaz and Rosenberg 2008). Health risks are another important cost associated with NPS pollution of waterways. One particularly dangerous consequence is growth of cyanobacteria, often called blue-green algae, which can produce neurotoxins that are harmful to animals and humans (Chorus et al. 2000). NPS pollution can also change consumers' preferences for 

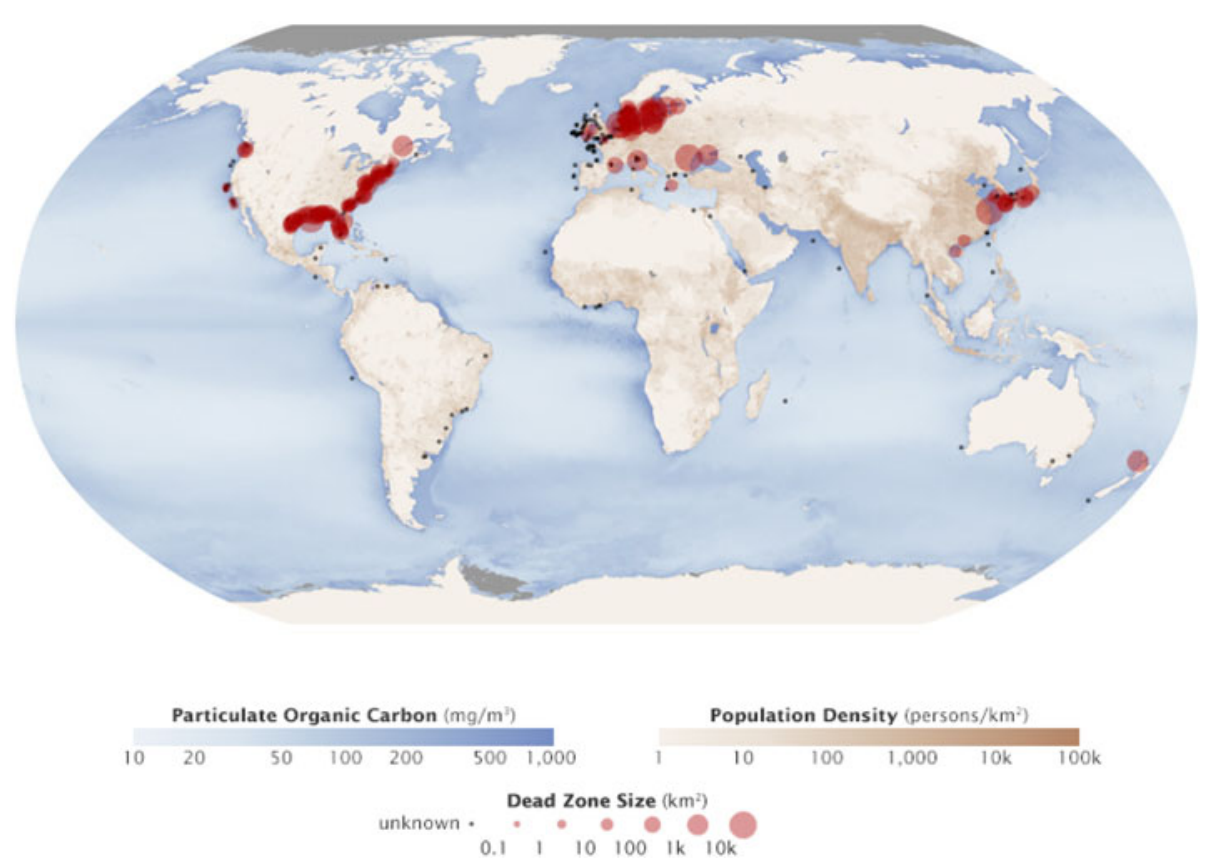

\section{Figure 1. Hypoxic Zones around the World}

Source: Diaz and Rosenberg (2008). Map by Robert Simmon and Jesse Allen based on data from (i) Robert Diaz, Virginia Institute of Marine Science (dead zones); (ii) the Goddard Space Flight Center Ocean Color team (particulate organic carbon); and (iii) the Socioeconomic Data and Applications Center (population density).

bottled water and their willingness to pay taxes for investments in wastewater treatment facilities. For countries that belong to the Organization for Economic Cooperation and Development (OECD), policies to address agricultural water pollution have cost taxpayers billions of dollars annually (OECD 2012) while still falling short of their targets.

Controlling NPS pollution from agricultural sources is a major naturalresource-management challenge. Much remains to be learned scientifically about the interaction of water quality and agricultural practices and about how to craft governance and regulatory systems that can transform knowledge into action (Kling 2011, Olmstead 2010). Uncertainty associated with this issue often relates to the geographic location of pollution, heterogeneous impacts of pollutants on water quality over space and time, appropriate valuations of changes in water quality, conflicts in governance of land and water systems, and the developing effects of climate change (Kling 2011, Olmstead 2010, Rabotyagov et al. 2010, Sigman 2002, Lipscomb and Mobarak 2008, Whitehead et al. 2009, Brainwood, Burgin, and Maheshwari 2004). Behavioral reactions to policies, valuations of NPS pollution, and 
spatial interdependence are particularly complex issues. Behavioral anomalies such as loss aversion, for example, can affect individuals' policy choices and valuations of water quality improvements. For markets and land-use management practices to be efficient, policymakers and regulators must account for the complicated interactions of time and space to understand the cumulative effects of water degradation in a watershed.

The many important issues related to water resources and quality point to the need for better policies that can specifically address obstacles to achieving efficient management of water quality. Existing institutions have made significant progress worldwide, but serious impediments remain.

The contributed papers in this special issue were presented at the Northeastern Agricultural and Resource Economics Association's Water Quality Economics Workshop in 2015 in Newport, Rhode Island, and directly address one or more of the challenges associated with NPS pollution and improving water quality.

\section{Contributions in this Special Issue}

The individual contributions in this issue inform policies, advance nonmarket valuations, or enhance understanding of behavioral economics associated with water quality by specifically addressing aspects that are unique to the complexities of water quality management, such as the mechanisms that transport pollution, which involve spatial considerations, transport delays, pollutant concentrations, ecosystem complexities, extreme weather events, and the presence and severity of any health risks. The papers also address social views of water as an environmental good, a private good, and an input/output in ecosystems that provide value through recreation, habitat, and mitigation of water quality. We next briefly highlight the particular contributions of each paper by topic.

\section{Valuation}

Numerous nonmarket methods can be applied when valuing water quality across multiple contexts. In this issue, valuations of water quality are addressed using hedonic valuation and experimental elicitation applied to contexts such as beach closures and contamination of ground water.

Fundamental questions remain regarding how private citizens value the degradation of water from NPS pollution and that information is essential for analyzing the costs and benefits of proposed policies aimed at reducing such pollution. Dennis Guignet, Patrick Walsh, and Rachel Northcutt (2016) examine the flow of nutrients from agricultural run-off into private ground water wells and assess valuations of decreased water quality through housing prices. They find significant depreciation in response to degraded water quality. Once the water quality is mitigated, however, the effect diminishes. This work illustrates the important role of water flows and 
externalities associated with various land uses and management practices in determining the external costs to homeowners, municipalities, and coastal communities.

Major challenges arise when comprehensively studying the costs and benefits of nonmarket services (such as ecosystem services) so studies of broader water-management initiatives usually require use of benefit transfer. Leah Palm-Forster, Frank Lupi, and Min Chen (2016) explore multiple benefittransfer functions applied to Lake Erie beaches to understand conditions that complement the more complicated functional benefit-transfer approach. For individual beach closures, they find that the relatively simple value transfer method produces nearly the same results as the more complicated functional transfer method. The results from the two approaches diverge, however, for closure of multiple beaches and the disparity grows with the number of beaches involved. The key insight from their work is that the simpler valuetransfer function does not account for substitutes for closed beaches, which can be critical to accurately assessing the cost of closing a beach and can have a substantial effect on estimates of outcomes when using benefittransfer methods.

\section{Experiments and Behavioral Biases}

Several studies in this special issue employ laboratory or field economic experiments and discuss behavioral anomalies related to environmental quality. These methods and insights are crucial for advancing our understanding of the economics of water quality because they elucidate the behavioral mechanisms that affect individuals' decisions about environmental quality measures and determine the effectiveness of policies established to improve water quality.

Several anomalies in behavior need to be better understood for water quality policies to be rational and effective. Gregory Poe (2016), in a manuscript based on his keynote speech at the workshop, provides a thorough review of the types of behavioral biases and anomalies identified in observed human behavior generally and shows that the same biases and anomalies are observed in participants in economic experiments and contingent-valuation exercises. Poe thus concludes that we should not reject stated-preference methods solely because they do not conform to economic theory.

One such important behavioral anomaly is a gap between willingness to accept (WTA) and willingness to pay (WTP). Pamela Booth, Todd Guilfoos, and Emi Uchida (2016) establish that the WTA-WTP gap exists for the quality of drinking water. While WTA-WTP gaps had been identified for a number of goods (Tunçel and Hammitt 2014), they had not been robustly investigated for changes in attributes of goods, such as the quality of water. This type of behavioral anomaly is likely to be important to voters who must consider tradeoffs involved in public decisions regarding conservation and 
preservation of the environment and investments in infrastructure to improve water quality.

Adaptation to climate change also plays an important role in managing water resources. Sean Ellis, Jacob Fooks, Kent Messer, and Matthew Miller (2016) explore how messaging related to climate change, extreme weather events, and decaying infrastructures affects individuals' willingness to contribute to organizations investing in clean water projects. They find that individuals are willing to give more to green infrastructure projects than to gray infrastructure projects. Particularly interesting is their finding that messages about extreme weather events generated the lowest probability of a contribution among the messages tested but also prompted relatively large contributions by the individuals who chose to give. Further research is needed to identify the best ways to motivate economic contributions to improving water quality, which will be especially important as climate change's effects on water quality become more pronounced.

\section{Nonpoint-source Pollution and Policies}

Three studies included in this issue speak to policies that control or affect how society confronts problems associated with NPS pollution from agricultural run-off. In particular, the papers emphasize the importance of spatial and temporal considerations when establishing water policies and constructing models to address complex water resources.

Markets for water quality have enjoyed some success in the United States in recent years so it is important to identify the types of markets and mechanisms that generate "correct" ratios for trading between sources to achieve economic efficiency. James Shortle, David Abler, Zach Kaufman, and Katherine Zipp (2016) investigate the importance of lags in the timing of releases of pollution and compare static markets to dynamically efficient markets. They find that static markets delay achievement of water quality targets but perform relatively well in terms of cost and performance. This research highlights the complex delivery mechanisms involved in water pollution and nutrient loading when measured at a censor downstream, such as Chesapeake Bay. Therefore, incorporating basic elements of the timing and spatial location of nutrient pollution is critical when evaluating the cost and effectiveness of a water quality market.

Biofuels can potentially contribute to reductions in carbon dioxide emissions and dependence on foreign oil but also involve tradeoffs with water quality degradation from nutrient loading. Adriana Valcu-Lisman, Catherine Kling, and Philip Gassman (2016) explore the tradeoffs associated with alternative land-use regimes and changes in water quality and habitat. They find that using switchgrass or miscanthus instead of soybeans or corn results in better water quality because those crops reduce soil erosion and nutrient uptake. Use of marginal land for biofuel is not a positive tradeoff overall. Their analysis of this simple policy demonstrates the importance of using 
computational spatial models of water and nutrient flows to determine outcomes in a complex system of soil erosion and nutrient transport. This type of research can illuminate inefficiencies in policies in a complex system and account for feedback from nonmarket prices, allowing for analysis of tradeoffs between market and nonmarket goods.

The effectiveness of cost-share programs and the programs' effects on water quality are still poorly understood. C.S. Kim and Todd Guilfoos (2016) present a hydrologic and economic model of ground water extraction and nutrient uptake to evaluate the implications for water quality of government subsidies (costshare programs) designed to encourage adoption of more-efficient irrigation technologies. They find that the cost-share program results in increased use of nitrogen fertilizer when the reduction in the rate of nitrate leaching is smaller than the increase in the rate of the marginal net economic benefit from using nitrogen fertilizer under the new irrigation technology.

\section{Discussion}

The research presented in this special issue makes valuable contributions to important areas of water quality economics. Many of the studies incorporated physical processes into the models or methods and found that geospatial and temporal considerations must be accounted for in economic analyses. Others focused on behavioral observations in the field and in the laboratory to provide insight into how individuals make economic decisions related to water quality and how the formation and effectiveness of policies can be influenced by such behavior. Much has been achieved in developing economically viable approaches to improving water quality, including establishment of nutrient trading markets and efforts under the Clean Water Act to improve the quality of surface water and drinking water sources. Economists can contribute to these ongoing efforts in part by determining which approaches have worked, which attempts have failed, and the reasons for those successes and failures. The papers included in this special issue lay the groundwork for a more thorough understanding of the complex systems that influence water quality around the world.

\section{References}

Brainwood, M.A., S. Burgin, and B. Maheshwari. 2004. "Temporal Variations in Water Quality of Farm Dams: Impacts of Land Use and Water Sources." Agricultural Water Management 70(2): 151-175.

Booth, P.L., T. Guilfoos, and E. Uchida 2016. "Endowment Effects and Drinking Water Quality." Agricultural and Resource Economics Review 45(2): 338-366.

Chorus, I., I.R. Falconer, H.J. Salas, and J. Bartram. 2000. "Health Risks Caused by Freshwater Cyanobacteria in Recreational Waters." Journal of Toxicology and Environmental Health Part B: Critical Reviews 3(4): 323-347.

Diaz, R.J., and R. Rosenberg. 2008. "Spreading Dead Zones and Consequences for Marine Ecosystems.” Science 321(5891): 926-929. 
Ellis, S.F., J.R. Fooks, K.D. Messer, and M.J. Miller 2016. "The Effects of Climate Change Information on Charitable Giving for Water Quality Protection: A Field Experiment." Agricultural and Resource Economics Review 45(2): 319-337.

Environmental Protection Agency. 2009. "National Rivers and Streams Assessment 20082009 Draft Report." EPA, Washington, DC.

—. 2015. "National Summary of State Information." EPA, Washington, DC. Available at https://ofmpub.epa.gov/waters10/attains_nation_cy.control\#total_assessed_waters (accessed May 10, 2016).

Guignet, D., P.J. Walsh, and R. Northcutt. 2016. "Impacts of Ground Water Contamination on Property Values: Agricultural Run-off and Private Wells." Agricultural and Resource Economics Review 45(2): 293-318.

Kling, C.L. 2011. "Economic Incentives to Improve Water Quality in Agricultural Landscapes: Some New Variations on Old Ideas." American Journal of Agricultural Economics 93(2): 297-309.

Kim, C.S., and T. Guilfoos. 2016. "The Effect of Cost-share Programs on Ground Water Exploitation and Nonpoint-source Pollution under Endogenous Technical Change." Agricultural and Resource Economics Review 45(2): 394-417.

Lipscomb, M., and A.M. Mobarak. 2008. "Decentralization and Water Pollution Spillovers: Evidence from the Redrawing of County Boundaries in Brazil." Working paper 67, International Policy Institute, University of Michigan, Ann Arbor.

Organization for Economic Cooperation and Development. 2012. "Water Quality and Agriculture: Meeting the Policy Challenge." OECD Publishing, Paris, France.

Olmstead, S.M. 2010. "The Economics of Water Quality." Review of Environmental Economics and Policy 4(1): 44-62.

Palm-Forster, L.H., F. Lupi, and M. Chen. 2016. "Valuing Lake Erie Beaches Using Value and Transfer Functions." Agricultural and Resource Economics Review 45(2): 270-292.

Poe, G.L. 2016. "Behavioral Anomalies in Contingent Valuation and Actual Choices." Agricultural and Resource Economics Review 45(2): 246-269.

Rabotyagov, S., T. Campbell, M. Jha, P.W. Gassman, J. Arnold, L. Kurkalova, S. Secchi, H. Feng, and C.L. Kling. 2010. "Least-cost Control of Agricultural Nutrient Contributions to the Gulf of Mexico Hypoxic Zone." Ecological Applications 20(6): 1542-1555.

Shortle, J., D. Abler, Z. Kaufman, and K. Zipp. 2016. "Simple vs. Complex: Implications of Lags in Pollution Delivery for Efficient Load Allocation and Design of Water-quality Trading Programs." Agricultural and Resource Economics Review 45(2): 367-393.

Sigman, H. 2002. "International Spillovers and Water Quality in Rivers: Do Countries Free Ride?" American Economic Review 92(4): 1152-1159.

Tunçel, T., and J.K. Hammitt. 2014. "A New Meta-analysis on the WTP/WTA Disparity." Journal of Environmental Economics and Management 68(1): 175-187.

UNICEF, World Health Organization. 2015. "Progress on Sanitation and Drinking Water: 2015 Update and MDG Assessment." World Health Organization, Geneva, Switzerland.

Valcu-Lisman, A.M., C.L. Kling, and P.W. Gassman. 2016. "The Optimality of Using Marginal Land for Bioenergy Crops: Tradeoffs between Food, Fuel, and Environmental Services." Agricultural and Resource Economics Review 45(2): 217-245.

Whitehead, P.G., R.L. Wilby, R.W. Battarbee, M. Kernan, and A.J. Wade. 2009. "A Review of the Potential Impacts of Climate Change on Surface Water Quality." Hydrological Sciences Journal 54(1): 101-123. 